\title{
Predictive Implication of Initial Electrocardiogram and Creatine Kinase for Left Ventricular Ejection Fraction in Patients with Acute ST-Elevation Myocardial Infarction
}

\section{Saeed Nourian*, Mohammad Reza Beyranvand, Zeinedin Kheiry, Ali Ali Asgari and Mohamad Asadpour Piranfar}

Tehran Heart Center, Teheran, Iran

${ }^{*}$ Corresponding author: Saeed Nourian, Tehran Heart Center, Poursina St., Ghods St., Keshavarz Blvd, Teheran, Iran, Tel: +98218802 9600; Fax: 98(21)8885 2654; E-mail: Sd.nourian@yahoo.com

Rec Date: Sep 05, 2016, Acc Date: Oct 27, 2016, Pub Date: Oct 30, 2016

Citation: Nourian S, Beyranvand MR, Kheiry Z, et al. Predictive Implication of Initial Electrocardiogram and Creatine Kinase for Left Ventricular Ejection Fraction in Patients with Acute ST-Elevation Myocardial Infarction. Interv Cardiol J 2016, 2:3.

\section{Abstract}

Aim: Our aim was to determine the clinical, electrocardiographic (ECG) and biochemical predictors of left ventricular dysfunction in patients with acute ST elevation myocardial infarction (STEMI).

Methods: Patients with STEMI admitted in Loghman Hakim hospital were studied. The ECG variables were: ECG rate, ECG rhythm, QRS duration, sum of absolute ST deviation (in all, inferior and anterior leads), number of leads with ST elevation, maximum ST elevation, presence of pathological $Q$ waves and location of the infarct. The primary outcome measure was LVEF $\leq 40 \%$.

Results: A total of 124 patients (91 male, 33 female) were studied. Mean age of the patients was 59.1 years ( $S D=12.6)$. Of these, 52 patients $(44.4 \%)$ had an LVEF $\leq$ $40 \%$ and angiography was recommended to 68 patients $(54.8 \%)$ at the time of discharge. The multivariate analysis showed an association of LVEF $\leq 40 \%$ with prior $\mathrm{MI}$, diabetes, maximum creatine kinase (CK) levels, the sum of absolute ST deviation in all and inferior leads.

Conclusions: The initial ECG and CK levels in patients with STEMI may contain valuable information for risk stratification, determination of prognosis and the subsequent management plan. The results of this study warrant further studies to define patients who benefit most from invasive and sophisticated interventions.

Keywords: Myocardial infarction; Electrocardiography; Creatine kinase; Risk assessment; Prognosis

\section{Introduction}

The electrocardiogram (ECG) is one of the most accessible diagnostic tools to evaluate the acute coronary syndrome. Changes involving the ST segment, $\mathrm{T}$ waves and pathologic $\mathrm{Q}$ waves in the ECG predict ischemic area, size and duration of ischemia [1] and the predictive value of ECG to determine mortality and other cardiac events (e.g. LV dysfunction, reinfarction) has been assessed in different studies [2,3]. In addition to ECG, biomarkers of myocardial necrosis like creatine kinase $(\mathrm{CK})$ and its muscle brain isomer (CK-MB) have been shown to be reliable for predicting the prognosis of patients with myocardial infarction [4]. Our aim was to assess the role of the initial electrocardiogram and CK levels in patients with acute STEMI to predict subsequent myocardial dysfunction.

\section{Patients and Methods}

This cross-sectional study enrolled 124 patients who were discharged with the final diagnosis of STEMI from Loghman Hakim hospital between October 2003 and April 2006. The following criteria were met for the diagnosis of STEMI: 1) symptoms of cardiac ischemia (chest pain) lasting more than 30 minutes, 2) ST-segment elevation of $\geq 1.0 \mathrm{~mm}$ in at least 2 contiguous leads and 3) subsequent typical rise and/or fall of CK levels (CKMB) [5]. Patients who showed confounding factors including history of congestive heart failure, left bundle branch block (either preexistent or new), ventricular pace rhythms, ventricular arrhythmias and those who lacked an initial ECG, three CK measurements or outcome data were excluded.

Patients' clinical and laboratory data were prospectively gathered and stored in a database for research purposes in the cardiology ward of Loghman Hakim hospital. Data from this database were analyzed for the study. In addition, 12-lead ECG recordings from patients were retrieved from hospital records and reviewed for the study. The initial ECG was the one that fulfilled the enrollment criteria and was used for analysis. A standard paper speed and amplification $(25 \mathrm{~mm}$ per second, $10 \mathrm{~mm} / \mathrm{mV}$ ) was applied. ST deviation (elevation or depression) was measured 60 milliseconds (ms) after the J point relative to the preceding TP segment. The definitions of ECG variables were used according to other similar studies [2]. CK (activity) sum was defined as the sum of three CK 
measurements, while CK max was the greatest value of CK measured.

The main outcome measures of the study were left ventricular ejection fraction (LVEF) $\leq 40 \%$ determined by echocardiography on days 3-5 after initial presentation. The patients with one of the following criteria had been recommended to carry out coronary angiography according to the guidelines of ACC/AHA [6]: 1) 1-14 days post MI angina; 2) sustained ventricular tachycardia (VT) or ventricular fibrillation (VF) after 48 hours of $\mathrm{Ml} ; 3$ ) congestive heart failure (CHF) symptoms and signs or ejection fraction (EF) $\leq 40 \%$; and 4 ) positive exercise tolerance test (ETT) or myocardial perfusion scan.

Quantitative variables are presented with mean \pm standard deviation. The qualitative variables are expressed with number and percent. The two groups of values were compared using the chi-square test. The independent samples t-test was used to compare the mean of quantitative variables in two groups. Univariate analysis was used to identify possible risk factors for the outcome measures. We used logistic regression analysis to identify independent and confounding variables. All variables with a statistical significance ( $p$-value) of at least 0.2 in the univariate analysis were selected for the final model. A value of $p<0.05$ was considered statistically significant. We used SPSS release 13.0 (SPSS Inc, Chicago, IL, USA) for all statistical tests.

\section{Results}

Table 1 Baseline characteristics of 124 patients with STEMI at Loghman Hakim hospital.

\begin{tabular}{|l|l|l|}
\hline Characteristics & Number & Percent \\
\hline Sex & & \\
\hline Male & 91 & 73.4 \\
\hline Female & 33 & 26.6 \\
\hline Risk factors & 33 & \\
\hline Hypertension & 23 & 26.6 \\
\hline Diabetes mellitus & 20 & 18.5 \\
\hline Prior myocardial infarction & 1 & 16.1 \\
\hline Renal failure & 43 & 0.8 \\
\hline Current or recent smoking & 34.7 \\
\hline Location of infarct (based & & \\
\hline
\end{tabular}

Location of infarct (based on ECG)

\begin{tabular}{|l|l|l|}
\hline Anterior & 52 & 41.9 \\
\hline Inferior & 65 & 52.4 \\
\hline Anterior and inferior & 6 & 4.8 \\
\hline Lateral & 1 & 0.8 \\
\hline
\end{tabular}

One hundred twenty-four eligible patients were reviewed. Their age ranged $33-84$ years (mean $59.1 \pm 12.6$ years). Inferior $\mathrm{Ml}$ was more frequents in patients $<50$-year-old in comparison to patients $\geq 50$-year-old, but wasnt significant statistically ( $61 \%$ vs $50 \%, p<0.24)$. Other baseline characteristics of the patients are shown in Table 1. The initial ECG showed sinus rhythm in 121 patients (97.6\%) and atrial fibrillation in 3 (2.4\%). Mean heart rate was $80.1 \pm 22.9$ beats per minute. Bradycardia was present in 16 patients $(12.9 \%)$ and tachycardia in 18 (14.5\%). Mean QRS duration was $72 \pm 17 \mathrm{~ms}$.

Echocardiography was performed in 117 patients (93.6\%) during admission. The mean LVEF was $45.2 \pm 11.3$. An LVEF $\leq$ $40 \%$ was found in 52 patients (44.4\%). Other complications after STEMI were: angina at rest in three patients $(2.4 \%)$, cardiac arrest in two (1.6\%) and pulmonary edema in another two patients.

The results of the univariate analysis to predict the outcome of LVEF $\leq 40 \%$ are presented in Tables $2 \mathrm{~A}$ and $2 \mathrm{~B}$. Based on these results, diabetes mellitus, prior myocardial infarction, CK sum, CK max, the sum of absolute ST deviation, the sum of ST deviation in inferior leads (II, III and aVF), number of leads with ST elevation and maximum ST elevation were selected for the multivariate analysis. Table $\mathbf{3}$ shows the results of the multivariate analysis.

\section{Discussion}

We found that the initial ECG and CK levels, which are readily available at any hospital, may provide important prognostic information and guide the subsequent treatment plan. The prognostic value of the initial ECG has been shown in several studies [2-4,7-10]. In one of the largest studies, Hathaway et al analyzed a clinical trial database of over 34000 patients and developed a nomogram to predict 30-day mortality in patients with STEMI who received thrombolytic therapy. Our study also addresses the utility of these simple diagnostic tests in terms of clinical decision making.

In several studies, even after primary $\mathrm{PCl}$ association of $\mathrm{CK}$ max with LV dysfunction and prognosis has been shown [11-14].

Risk factors for coronary artery disease in our patients and studies from western countries are compared in Table 4 . The frequency of prior $\mathrm{MI}$ and diabetes mellitus were similar in our patients and other studies, but hypertension and smoking were found more frequently in patients from western countries. This difference warrants further investigation and may be the reason for the lack of association of these factors in our study. Coronary angiography was recommended to 68 patients $(54.8 \%)$ at the time of discharge. (Indications of angiography were EF $\leq 40 \%$ in $75 \%$, positive ETT and positive perfusion scan in $12 \%$, post $\mathrm{Ml}$ angina in $11 \%$ and cardiac arrest in $2 \%$ of patients).

In two large studies with sample sizes of over 34000 and 12000 patients, several ECG variables were found to be related to clinical outcomes, including 30-day mortality [2,3]. However, results of studies based on data of patients enrolled in clinical trials should be interpreted with caution, because: 1 ) in the actual practice, it is not possible to administer thrombolytic therapy to all patients with STEMI due to contraindications or 
late presentation of the patient and 2) trial populations have better outcomes than do general unselected populations.

Table 2A: Univariate associations for LVEF $\leq 40 \%$ in 117 patients with STEMI. categorical variables (percent).

\begin{tabular}{|l|l|l|}
\hline Variable & $\mathrm{EF} \leq \mathbf{4 0} \%$ & $\mathrm{EF}>\mathbf{4 0} \%$ \\
\hline Sex & & \\
\hline Male & 73.1 & 75.4 \\
\hline Female & 26.9 & 24.6 \\
\hline Hypertension & 26.9 & 26.2 \\
\hline Prior MI & 23.1 & 7.7 \\
\hline Diabetes mellitus & 25 & 13.8 \\
\hline Smoking & 32.7 & 33.8 \\
\hline Thrombolytic therapy & 44 & 50.8 \\
\hline Pathological Q waves & 53.8 & 46.2 \\
\hline
\end{tabular}

Table 2B: Continuous variables (mean \pm standard deviation).

\begin{tabular}{|l|l|l|}
\hline Variable & $\mathrm{EF} \leq \mathbf{4 0} \%$ & $\mathrm{EF}>\mathbf{4 0} \%$ \\
\hline Age (years) & $59.9 \pm 13.3$ & $58.5 \pm 12.5$ \\
\hline CK sum (mg/dl) & $4460.2 \pm 3484.5$ & $2478.4 \pm 1660.7$ \\
\hline CK max (mg/dl) & $2518.3 \pm 1909.0$ & $1381.6 \pm 975.9$ \\
\hline $\begin{array}{l}\text { ECG rate (beats per } \\
\text { minute) }\end{array}$ & $81.4 \pm 22.7$ & $78.7 \pm 22.6$ \\
\hline QRS duration (ms) & $70.2 \pm 16.0$ & $72.3 \pm 15.2$ \\
\hline $\begin{array}{l}\text { Sum of ST deviation in all } \\
\text { leads (mm) }\end{array}$ & $15.6 \pm 9.1$ & $10.4 \pm 6.0$ \\
\hline $\begin{array}{l}\text { Sum of ST deviation in } \\
\text { inferior leads (mm) }\end{array}$ & $2.9 \pm 2.8$ & $3.7 \pm 2.7$ \\
\hline $\begin{array}{l}\text { Sum of ST deviation in } \\
\text { leads V1-V4 (mm) }\end{array}$ & $7.9 \pm 5.7$ & $3.6 \pm 3.9$ \\
\hline $\begin{array}{l}\text { Number of leads with ST } \\
\text { elevation (mm) }\end{array}$ & $5.9 \pm 1.8$ & \pm 1.7 \\
\hline
\end{tabular}

Table 3: Multivariate odds ratios and $95 \%$ confidence intervals for predictors of left ventricular dysfunction (LVEF $\leq 40 \%$ ) in 117 patients with STEMI.

\begin{tabular}{|l|l|l|}
\hline Variable & $\begin{array}{l}\text { Odds } \\
\text { ratio }\end{array}$ & $\mathbf{9 5 \%} \mathbf{C l}$ \\
\hline Prior MI & 6.1 & $1.6-23.2$ \\
\hline Diabetes mellitus & 2.6 & $0.8-8.2$ \\
\hline CK max $(\times 1000 \mathrm{mg} / \mathrm{dl})$ & 2 & $1.3-2.9$ \\
\hline Sum of ST deviation in all leads $(\mathrm{mm})$ & 1.1 & $1.1-1.2$ \\
\hline Sum of ST deviation in inferior leads $(\mathrm{mm})$ & 0.7 & $0.6-0.9$ \\
\hline
\end{tabular}

Table 4: Comparison of the distribution of risk factors for coronary artery disease in our patients and studies from western countries.

\begin{tabular}{|l|l|l|l|l|}
\hline Risk factor & $\begin{array}{l}\text { Current } \\
\text { study }\end{array}$ & $\begin{array}{l}\text { Hathaway } \\
\text { et al. [2] }\end{array}$ & $\begin{array}{l}\text { Savonitto } \\
\text { et al. [3] }\end{array}$ & $\begin{array}{l}\text { Manes et } \\
\text { al. [7] }\end{array}$ \\
\hline Hypertension & $27 \%$ & $38 \%$ & $41 \%$ & $41 \%$ \\
\hline Diabetes & $18 \%$ & N/A & $17 \%$ & $21 \%$ \\
\hline Prior MI & $16 \%$ & $16 \%$ & $20 \%$ & $16 \%$ \\
\hline Smoking & $35 \%$ & N/A & $40 \%$ & N/A \\
\hline \multicolumn{2}{|l|}{ N/A: not available. } & & & \\
\hline
\end{tabular}

The frequency of the need for angiography in our patients (55\%) was similar to the rate of coronary angiography performed during hospitalization (57\%) in other studies [3].

The results of this study should be interpreted in the context of their limitations. Our results apply only to the initial ECG and serial ECGs were not analyzed in this study. Because the ST segment fluctuates throughout an infarction and rhythm disturbances may be transient, analysis of the "worst" ECG tracing would likely alter our results. The same concept applies to the LVEF. Studies have shown that recovery of LV function may be observed up to 90 days after MI. Therefore, an echocardiography performed a few days after MI may not show the long-term function of the left ventricle. The use of more sensitive and specific biochemical markers of myocyte injury (e.g. troponin) might improve the power of enzymatic risk stratification.

\section{Conclusions}

The initial ECG and CK levels in patients with STEMI may contain valuable information for risk stratification, determination of prognosis and the subsequent management plan.

\section{References}

1. Asch FM, Shah S, Rattin C, Swaminathan S, Fuisz A, et al. (2006) Lack of sensitivity of the electrocardiogram for detection of old myocardial infarction: A cardiac magnetic resonance imaging study. Am Heart J 152: 742-748.

2. Hathaway WR, Peterson ED, Wagner GS, Granger CB, Zabel KM, et al. (1998) Prognostic significance of the initial electrocardiogram in patients with acute myocardial infarction. GUSTO-I Investigators. Global Utilization of Streptokinase and tPA for Occluded Coronary Arteries. JAMA 279: 387-391.

3. Savonitto S, Ardissino D, Granger CB, Morando G, Prando MD, et al. (1999) Prognostic value of the admission electrocardiogram in acute coronary syndromes. JAMA 281: 707-713.

4. Nienhuis MB, Ottervanger JP, de Boer MJ, Dambrink JH, Hoorntje JC, et al. (2008) Prognostic importance of creatine kinase and creatine kinase-MB after primary percutaneous coronary intervention for ST-elevation myocardial infarction. Am Heart J 155: 673-679.

5. Cannon CP, Battler A, Brindis RG, Cox JL, Ellis SG, et al. (2001) American College of Cardiology key data elements and definitions for measuring the clinical management and outcomes of patients with acute coronary syndromes. A report of the American College of Cardiology Task Force on Clinical 
Data Standards (Acute Coronary Syndromes Writing Committee). J Am Coll Cardiol 38: 2114-2130.

6. Antman EM, Anbe DT, Armstrong PW, Bates ER, Green LA, et al. (2004) ACC/AHA guidelines for the management of patients with ST-elevation myocardial infarction: a report of the American College of Cardiology/American Heart Association Task Force on Practice Guidelines (Committee to Revise the 1999 Guidelines for the Management of Patients with Acute Myocardial Infarction). Circulation 110: e136.

7. Manes C, Pfeffer MA, Rutherford JD, Greaves S, Rouleau JL, et al. (2003) Value of the electrocardiogram in predicting left ventricular enlargement and dysfunction after myocardial infarction. Am J Med 114: 99-105.

8. Birnbaum Y, Criger DA, Wagner GS, Strasberg B, Mager A, et al. (2001) Prediction of the extent and severity of left ventricular dysfunction in anterior acute myocardial infarction by the admission electrocardiogram. Am Heart J 141: 915-924.

9. Sarasso G, Aralda D, Makmur J, Francalacci G, Campini R, et al. (1983) Short-term prognostic evaluation of acute myocardial infarct: comparison of 2-dimensional echocardiography, electrocardiography, and the MB-CK index. G Ital Cardiol 13: 11-20.
10. Sadanandan S, Hochman JS, Kolodziej A, Criger DA, Ross A, et al. (2003) Clinical and angiographic characteristics of patients with combined anterior and inferior ST-segment elevation on the initial electrocardiogram during acute myocardial infarction. Am Heart J 146: 653-661.

11. Turer AT, Mahaffey KW, Gallup D, Weaver WD, Christenson RH, et al. (2005) Enzyme estimates of infarct size correlate with functional and clinical outcomes in the setting of ST-segment elevation myocardial infarction. Curr Control Trials Cardiovasc Med 6: 12

12. Raymond JG, Uma SV, Philip AA, Allan SJ (2004) The quantification of infarct size. JACC 44: 1533-1542.

13. Thompson PL, Fletcher EE, Katavatis V (1979) Enzymatic indices of myocardial necrosis: influence on short- and long-term prognosis after myocardial infarction. Circulation 59: 113-119.

14. Halkin A, Stone G, Grines C, Cox D, Rutherford B, et al. (2008) Prognostic Implications of creatine kinase elevation after primary percutaneous coronary intervention for acute myocardial infarction . JAAC 47: 951-961. 